\section{Aerosol and Air Quality Research}

Special Issue:

Pulmonary and Neurological Health Impacts from Airborne Particulate Matter (IV)

\section{OPEN ACCESS}

Received: September 21, 2020

Revised: January 30, 2021

Accepted: February 12, 2021

${ }^{*}$ Corresponding Author:

chrystelle.ibanez@irsn.fr

\section{Publisher:}

Taiwan Association for Aerosol Research

ISSN: $1680-8584$ print ISSN: 2071-1409 online

Copyright: The Author(s). This is an open access article distributed under the terms of the Creative Commons Attribution License (CC BY 4.0), which permits unrestricted use, distribution, and reproduction in any medium, provided the original author and source are cited.

\section{Design of an Inhalation Chamber and Metrology Assessment to Study Tungsten Aerosol Neurotoxic Effects}

\author{
Léo Macé, Chrystelle Ibanez*, Thomas Gelain, Cécile Bodiot, Laure Juhel, \\ François Gensdarmes
}

Institut de Radioprotection et de Sûreté Nucléaire (IRSN), Fontenay-aux-Roses cedex, 92262, France

\section{ABSTRACT}

To evaluate the neurotoxic effects from exposure to airborne tungsten, we developed a method of generating mass concentrations of this element between 5 and $10 \mathrm{mg} \mathrm{m}^{-3}$, the timeweighted average occupational exposure limits. We then conducted measurements of the aerosol-a challenge due to the high particle density-that enabled us to calculate the deposition in the upper airway and lungs.

First, we fed a mixture of coarse tungsten bead powder and aerosolizable tungsten powder,

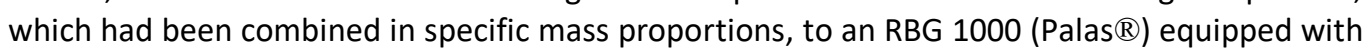
a cyclone at the outlet that filtered out the coarse particles. Then, we simultaneously measured the resultant aerosol, which was generated in an inhalation chamber, using three pairs of instruments-a Dekati ${ }^{\circledR}$ Low Pressure Impactor (DLPI; $30 \mathrm{~L} \mathrm{~min}^{-1}$ ) and a gravimetric filter holder, a DLPI and a TSI® Aerodynamic Particle Sizer (APS; Model 3321), a TSI Engine Exhaust Particle Sizer (EEPS; Model 3090) and an APS-and symmetrical sampling lines.

The mass concentrations obtained with the DLPI and the filter holder were extremely consistent with each other, and the mass median aerodynamic diameters based on the DLPI and the APS data (with the Stokes correction applied to the latter) were also fairly close (1.77 and $1.89 \mu \mathrm{m}$, respectively). Additionally, the count median diameter determined from the electrical mobility measured by the EEPS equaled $0.17 \mu \mathrm{m}$, which falls beyond both the intended range of the instrument and the range of previously studied aerodynamic sizes.

Overall, the results from the DLPI, the APS, and the EEPS showed very good agreement. Computational fluid dynamics (CFD) simulations of the airflows and aerosol dispersion in the inhalation chamber verified that the test aerosol was homogeneous and representative.

Keywords: Tungsten, Inhalation, Particle density, Neurotoxicology

\section{INTRODUCTION}

Health issues linked to air pollution exposure become a central focus, not only for their impact on the pulmonary system, but also for their potential hazardous effects in the brain. In the last decade, a growing number of epidemiological studies have reported incidence of neurodegenerative diseases and cognitive impairments in people exposed to particulate pollutants commonly encountered in metropolitan areas. Among them, Oudin et al. (2016) have suggested that longterm exposure to traffic-related air pollution could be associated with increased risk of vascular dementia and Alzheimer's disease in a major city in northern Sweden (Oudin et al., 2016). In the United States, another epidemiological study has identified an association between pre- and postnatal air pollution exposure and autism spectrum disorder. The critical window of exposure appeared to be during the late prenatal period and first year of life (McGuinn et al., 2019). In Mexico City, postmortem analyses performed on children that were exposed to high air pollution 
revealed lesions in the prefrontal cortex, in particular in white matter areas (Calderon-Garciduenas et al., 2016).

The demonstration of a link between inhalation of particulate pollutants and harmful biological effects on the brain is an emerging issue. This risk concerns the global population due to numerous pathways of exposures both environmental and occupational. There is indeed increased number of experimental studies showing that the brain could be a direct target after inhalation of particulate matter (PM) (Oberdorster et al., 2009; Lucchini et al., 2012; Heusinkveld et al., 2016). In those studies, neuroinflammation appears as the primary process mediating the deleterious effects of PM exposures (Jayaraj et al., 2017). Literature indeed reports activation of microglial cell as revealed by the increase of pro-inflammatory cytokines levels in rat brains after exposure to diesel exhaust (DE) and diesel nanoparticles (Levesque et al., 2011). Microglial cell activation has also been demonstrated in male mice after prenatal exposure to DE particles (Bolton et al., 2017). A recent study showed that inhalation of titanium dioxide nanoparticles induced alterations of the blood-brain barrier in rats, associated with increased expression of pro-inflammatory cytokines and more pronounced with age (Disdier et al., 2017). Neuroinflammation is then thought to alter brain cell integrity; in particular, it causes neurogenesis impairments as demonstrated by Coburn et al. (2018).

The cerebral effects of PM appear to be mediated by the direct transfer of particulate pollutants from the nasal cavity to the brain, also called "nose-to-brain pathway," in addition to the systemic pathway. Biokinetic studies were conducted to follow the distribution of metal particles after inhalation in various organs including the brain. Exposure via inhalation of titanium dioxide and lead oxide nanoparticles led to translocation in rodent brain (Dumkova et al., 2017; Pujalte et al., 2017). Direct transfer of uranium to the brain has also been demonstrated in rats after intranasal instillation of solubilized compound (Ibanez et al. , 2014) and inhalation of $\mathrm{UO}_{4}$ particles as aerosol (Ibanez et al., 2019). Other particulate elements have been proposed for a direct olfactory transport to the brain after exposure of upper airways: carbon (Oberdorster et al., 2004), manganese (Elder et al., 2006), ferric oxide (Wang et al., 2011) and silver nanoparticles (Wen et al., 2016).

The main cause of contamination during nuclear occupational activities is via inhalation of airborne PM. Concern is raised in terms of potential health risks for exposed workers, in particular in mines, during nuclear fuel cycle operations, and dismantling of nuclear facilities (Anderson et al., 2016; Samson et al., 2016). These activities can result in particle resuspension or direct emission of aerosols (Peillon et al., 2017; Chae et al., 2019) in the air in workplace areas.

Another particular case is related to nuclear fusion reactors since the divertor of the tokamak reactor is made of tungsten. A significant production of particles is expected in the vacuum chamber during the reactor operation due to the erosion process caused by the plasma. Personnel may be exposed to aerosolized tungsten particles during maintenance operations or accidental situations which require specific health risk and environmental consequences assessment. Several studies shows that these tungsten particles from eroded reactor walls are polydispersed with size ranging from 0.1 to $30 \mu \mathrm{m}$ (Rondeau et al., 2015).

Tungsten appears as an emerging toxicant (Bolt and Mann, 2016; Wasel and Freeman, 2018). It is used in hard metal industry, in new technologies using nanoparticles, in military alloys, and is present in the extraction mines environment. Tungsten exposure situations could be encountered more often in the future, in particular due to decommissioning operations of specific industrial sites including nuclear facilities, such as the European Spallation Source (ESS) or tokamaks for fusion research.

The first report of the Agency for Toxic Substances and Disease Registry (ATSDR) on tungsten toxicity in 2005 has been updated in 2015 (ATSDR, 2015). Among the new studies it describes a biokinetic experiment examining tungsten distribution in the lungs, liver, kidney, femur and brain after particle inhalation in rats (Radcliffe et al., 2010). As a primary target organ of inhalation exposures, lung has been mostly studied to target the potential effects of tungsten particles of various physicochemical forms. Experimental studies have demonstrated an increase in inflammation and oxidative stress processes as well as histological impairments in rodent lungs after exposure of upper airways to tungsten (Roedel et al., 2012; Prajapati et al., 2017). Very recently, using two in vitro models, BEAS-2B cells and 3D human airway epithelium model, differential responses to tungsten were documented: epigenotoxic alterations and transient inflammatory response (George et al., 2019; Uboldi et al., 2019). 
Brain also appears to be sensitive to tungsten exposure. Electrophysiological recordings revealed impairments in the opening of voltage-dependent channels involved in action potential generation in brain slices exposed to tungsten (Shan et al., 2013). In vivo, tungsten administration increased the expression of biomarkers of oxidative stress and modulated the production of neurotransmitters (Sachdeva et al., 2015). Similar to other metals, elemental tungsten is thought to follow the olfactory pathway to reach the brain as observed in a rodent experimental model after inhalation of radiolabeled sodium tungstate $\left({ }^{188} \mathrm{~W}\right)$ which is a water-soluble compound (Radcliffe et al., 2009).

Tungsten is indeed the metal selected in this study. As this study aims at generating new knowledge on the effect of tungsten particle inhalation on brain, it appears crucial to develop a new in vivo exposure set-up. This will allow fine control of the size distributions of tungsten aerosols in our nose-only inhalation chamber.

The critical step of inhalation chamber design is extensively described in the literature. Two different experimental set-ups can be encountered, whole-body and nose-only exposures, both having specific advantages and drawbacks. In whole-body exposure, the subject is entirely immersed in the atmosphere inside the chamber. It is supposed to simulate situation of environmental or workplace exposures. Early chambers were described as early as the 1970s (Carlini, 1973). New models have been developed to evaluate the effect of different types of pollutants after inhalation and are described in the literature (Rihn et al., 1996; Matthew et al., 2001). The main issue of these chambers is ingestion of the pollutant that has deposited on the fur and variation of uptake among animals.

The second experimental set-up is much more specific to upper airways contamination studies due to the use of a head and nose-only exposure systems. This means that only the nose of the animal will be in contact with the aerosol. Contention tubes directly connected to the chamber can be used for smaller animals such as rodents (Phalen, 1997; Chen and Lippmann, 2015). Several laboratories are using this set-up with an inhalation tower around which the contention tubes are set up. In those systems, the airflow containing the inhaled compound is highly controlled and the aerosol metrology is carried out thoroughly (Buckley et al., 2017; Gate et al., 2019; Lucci et al., 2019). These articles point out the fact that all parameters deserve to be closely monitored: particles size distribution and concentration, airflow within the chamber, animal position and breath rate.

Literature shows that in order to perform the most realistic exposure and atmospheres, extensive measurements of various parameters must be performed in inhalation boxes. In this study, we describe the set-up of a methodological strategy to control the generation of a tungsten aerosol to reach a concentration close to the average occupational exposure limit value (AOEL), between 5 and $10 \mathrm{mg} \mathrm{m}^{-3}$ according to the conventional respiratory fractions that are considered in France. It should be noted that there is a consensus on these values at the European level and also in the United States. Some countries may additionally specify whether this limit value concerns the inhalable or alveolar fractions, and whether it concerns an activity over a full working day (8 hours) or a short-duration activity (15 minutes).

\section{METHODS}

\subsection{Tungsten Particle Characteristics and Issues on Metrology of High-density Particle}

Pure and non-porous metal tungsten particles have extremely high density $\left(19,300 \mathrm{~kg} \mathrm{~m}^{-3}\right)$. With regard to aerosol metrology, this very high density implies that at the same mass concentration, the number concentration of a tungsten aerosol will be more than one order of magnitude lower than that of a more conventional aerosol with density particles of about $1000 \mathrm{~kg} \mathrm{~m}^{-3}$. Let provide the orders of magnitude, a concentration of $1000 \mathrm{p} \mathrm{cm}^{-3}$ of spherical tungsten particles of $1 \mu \mathrm{m}$ corresponds to a mass concentration of $10 \mathrm{mg} \mathrm{m}^{-3}$. In addition, there is a very large difference between the diffusion or electrical mobility diameter and the aerodynamic diameter of the particles. The smaller the particle size is, the larger the difference. Indeed, in the submicronic domain, the ratio of Cunningham coefficients corresponding to the electrical mobility diameter and aerodynamic diameter plays a major role. For spherical and non-porous particles, these two diameters are 
linked by the following equation (DeCarlo et al., 2004):

$$
\rho_{0} \cdot D_{a}^{2} \cdot C u\left(D_{a}\right)=\rho_{p} \cdot D_{m}^{2} \cdot C u\left(D_{m}\right)
$$

where $D_{m}$ is the electrical mobility diameter, $\rho_{p}$ is the density of the constituent material, $C u$ is the Cunningham correction factor (its value is very close to 1 for diameters greater than $3 \mu \mathrm{m}$ ), $\rho_{0}$ is the reference density $\left(\rho_{0}=1000 \mathrm{~kg} \mathrm{~m}^{-3}\right)$ and $D_{a}$ is the aerodynamic diameter.

\subsection{Experimental Device and Set-up}

The inhalation chamber is based on the initial design as described by André et al. (1989). The volume of the chamber is $47.5 \mathrm{~L}(52 \mathrm{~cm} \times 59 \mathrm{~cm} \times 15.5 \mathrm{~cm}$; Fig. 1). Inside the chamber, two plexiglass fins are attached onto one of the walls and flush with the opposite wall. Their function is to promote the homogenization of the aerosol inlet from the upper part of the chamber and to avoid excessive airflow velocities close to the areas where animals inhale the aerosol. These airflow velocities are related to the airflow created by the airstream at the injection point. The aerosol is vented by two exhausts located on the right and left of the aerosol entry. Fig. 1 shows a diagram of the experimental set-up with the inhalation chamber.

The inhalation chamber is equipped with thin-wall sampling probes with a diameter $(12 \mathrm{~mm})$ that meets the Davies criteria for still air sampling of particles up to $5 \mu \mathrm{m}$ in terms of aerodynamic diameter with a sampling flow rate of $10 \mathrm{~L} \mathrm{~min}^{-1}$ (Davies, 1968). A $30 \mathrm{~mm}$ diameter orifice is used for larger flow rate sampling. The design of the chamber has been determined for a flow rate compatible with the physiological needs of rats. In our conditions the injection at 2.5 bar has been chosen to allow to reach the target concentration for an exposure of 10 animals. The temperature and humidity in the chamber containing the tubes is controlled in real time, and varies between $20^{\circ} \mathrm{C}$ and $23^{\circ} \mathrm{C}$ for about $50 \%$ humidity.

To generate an aerosol of tungsten particles with a mass concentration in the order of the average occupational exposure limit value (VME) that is $10 \mathrm{mg} \mathrm{m}^{-3}$ and a flow rate of about $40 \mathrm{~L} \mathrm{~min}^{-1}$, the choice was made to use a rotating brush generator (RBG 1000; Palas) filled with a calibrated tungsten powder (Fig. 2). Considering the operating conditions of this generator, the
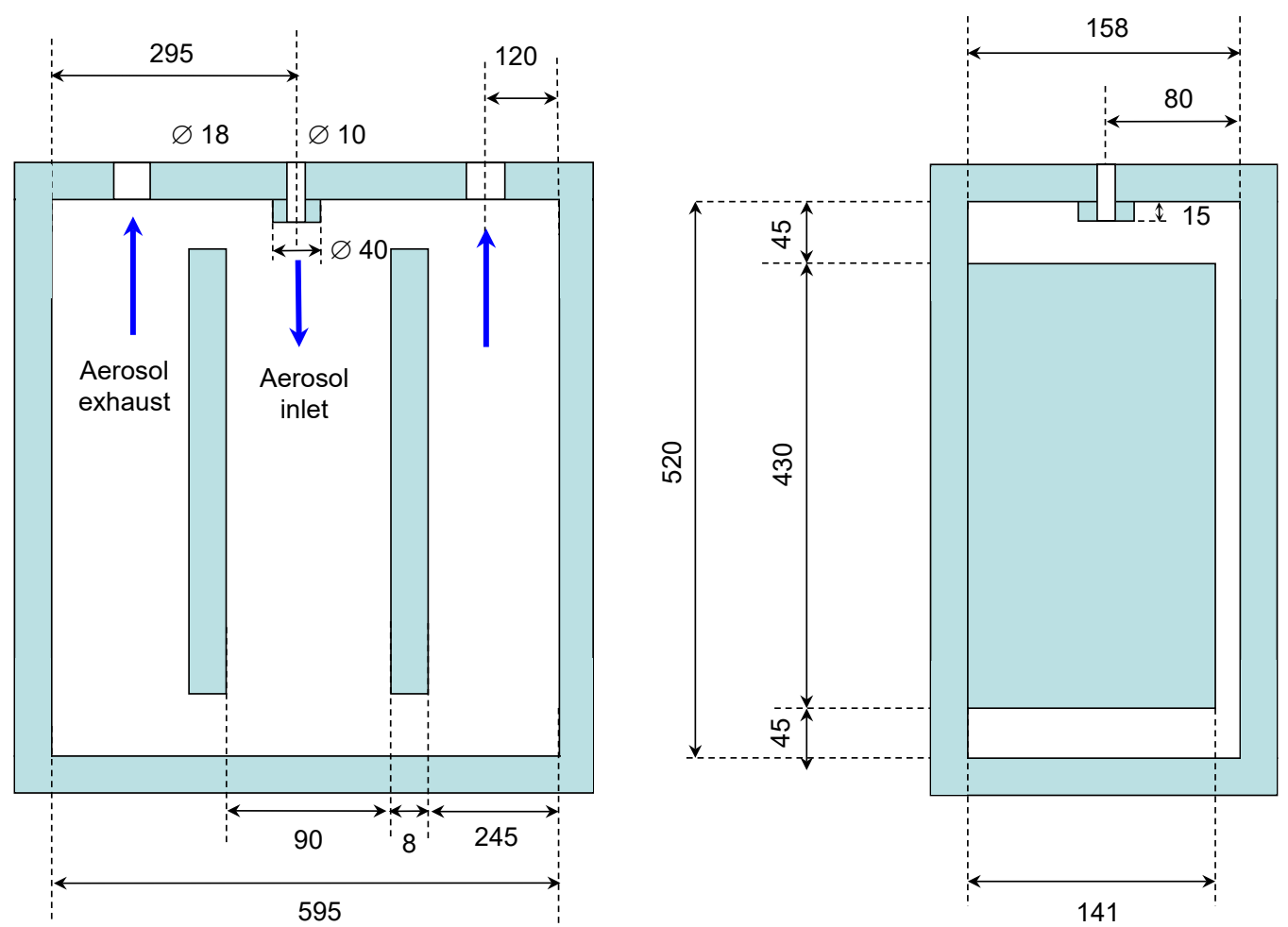

Fig. 1. Inhalation chamber: front and side view. 


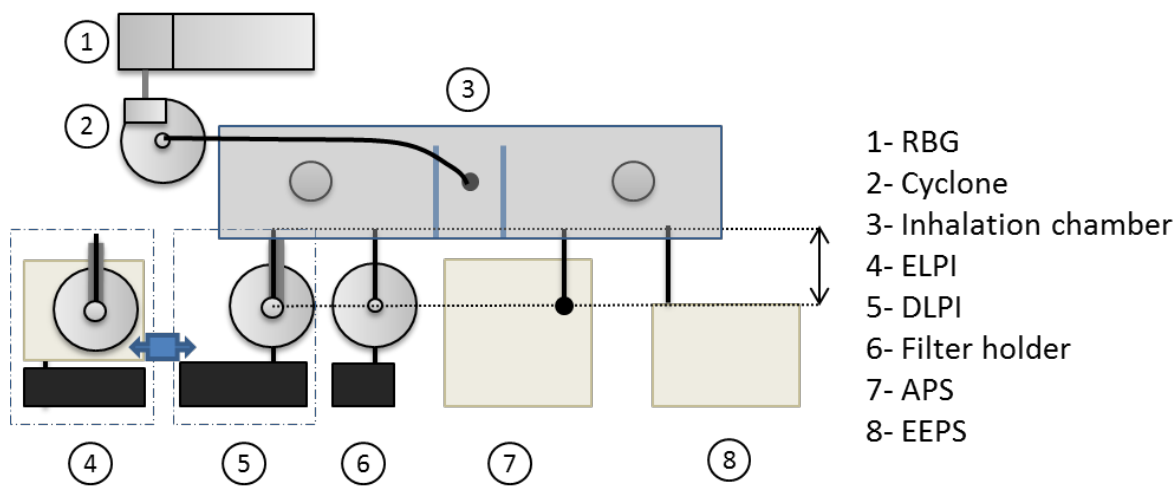

Fig. 2. Experimental set-up: top view illustrating the positioning of the different instruments.

aerosol concentrations produced are generally very high and this requires the use of a downstream aerosol dilution system. This disadvantage, in addition to the very high density of the tungsten powder, led us to use a solution consisting in diluting the powder to be dispersed rather than the aerosol produced. For this purpose, we mix the powder of interest to be dispersed (mean grain size $0.5-0.6 \mu \mathrm{m}$ from manufacturer data sheet, $99.9 \%$ metal W purity; A-20; A.L.M.T. Corp.) with a tungsten bead powder having a relatively large diameter (mean bead size $25 \mu \mathrm{m}$ from manufacturer data sheet, $99.9 \%$ metal W purity; $\mathrm{W}-25$; Tekna) in well-defined mass proportions, i.e., $20 \% \mathrm{~A}-20$ and $80 \% \mathrm{~W}-25$. To obtain the aerosol of interest, we use a cyclone at the outlet of the RBG 1000 to remove large particles from the dilution powder and also fine powder particles aggregates (Fig. 2). The cyclone was sized using the scaling software developed by Sagot et al. (2017) and based on its work on compact cyclone published by his team. The cyclone calculation is realized with a barrel diameter, D, equal to $60 \mathrm{~mm}$, and the 1D1D design referred to as SFYB in the original Sagot's paper. The aerodynamic cut-off diameter calculated is $8 \mu \mathrm{m}$ for a flow rate equal to $42 \mathrm{~L} \mathrm{~min}^{-1}$ in STD conditions $\left(20^{\circ} \mathrm{C}\right.$ and $1013 \mathrm{hPa}$ ). Before exposure, the $10 \mathrm{~mm}$ (internal diameter) piston from the RBG 1000 is filled at $75 \%$, which represents about $1.5 \mathrm{~g}$ of the mixture A-20-W-25. In normal use the piston is refilled after 3 sessions of exposures at low concentration, and between each exposure at high concentration. The filling of the piston is carried out by the same operator who performs a low powder compaction in order to avoid variability inside the piston. This filling method was selected during the stability measurements.

Several tests of repeatability and stability of the aerosol concentration generated in the chamber where realized by measurement in real time over 60 min sessions, then the operation of the RBG 1000 generator coupled to the cyclone was set with the following parameters: piston speed at $10 \mathrm{~mm} \mathrm{~h}^{-1}$, inlet pressure $1.5 \mathrm{bar}$, outlet flow rate $42.5 \mathrm{~L} \mathrm{~min}^{-1}$, dispersion hood type $\mathrm{B}$, brush rotation speed at 1200 rotations per minute $(\mathrm{rpm})$. Measurements on the aerosols produced in the chamber were made with different instruments used in pairs with sampling lines symmetrically disposed on the chamber as presented in Fig. 2. Therefore, measurements were carried out simultaneously thanks to a Dekati ${ }^{\circledR}$ Low Pressure Impactor (DLPI; $30 \mathrm{~L} \mathrm{~min}^{-1}$ ) and a gravimetric filter holder, a DLPI and a TSI ${ }^{\circledR}$ Aerodynamic Particle Sizer (APS; Model 3321), a TSI Engine Exhaust Particle Sizer (EEPS; Model 3090) and an APS, and a Dekati Electrical Low Pressure Impactor (ELPI) and an APS.

\subsection{CFD Simulations of Airflows and Aerosol Dispersion in the Inhalation Chamber}

In order to evaluate the spatial homogeneity of particles concentration in the inhalation chamber, especially near the areas where animals inhale the aerosol, CFD simulations of the airflows and aerosols dispersion in the chamber were performed with the commercial code ANSYS CFX. Knowledge of airflow velocities close to the nose of animals is also important to ensure representativeness when using particles inhalation and deposition models in airways.

The calculations were performed, based on the geometry of the inhalation chamber, designed with the software ANSYS Design Modeler. The geometry designed from dimensions of the diagram of the inhalation chamber is presented in Fig. 1. It has to be noticed that the holes of the 
Table 1. Parameters adopted for the CFD calculations.

\begin{tabular}{ll}
\hline Boundary Conditions & \\
\hline Air inlet flow rate & $42 \mathrm{~L} \mathrm{~min}^{-1}$ \\
Particles aerodynamic diameter & $2 \mu \mathrm{m}$ \\
Deposition on the wall & Sink term of deposition (Sdep; Nerisson et al., 2011) \\
\hline Numerical Parameters & \\
\hline Turbulence model & $\mathrm{k}-\omega \mathrm{SST}$ \\
Discretization scheme & Hybrid scheme (between first and second order) \\
Calculation type & Stationary \\
Timescale & Physical timescale equal to $0.1 \mathrm{~s}$ \\
\hline
\end{tabular}

tubes where the animals are located are not represented. It was considered that the small animal breathing flow rate has no influence on the airflows close to the wall inside the chamber.

The geometry was meshed with the software ANSYS Meshing. It contains around 1.2 million of tetrahedral elements, as presented in Fig. S1. The minimum mesh size is $1 \mathrm{~mm}$ and the maximal mesh size is $1 \mathrm{~cm}$. A mesh refinement, corresponding to a dimensionless distance $\left(\mathrm{y}^{+}\right.$; Sclichting, 1979) lower than 10, was set on the face where the animals inhale the aerosol in order to calculate the airflow as close to the wall as possible.

The dataset for calculations was defined on the basis on the input data and boundary conditions obtained from the experiments. The conditions are summarized in Table 1.

The calculations were processed by resolving the Navier-Stokes equations into which models of aerosol transport and deposition developed by Nérisson et al. (2011) were included by our team.

In order to optimize the numerical parameters, sensitivity studies of the turbulence model and of the meshing were performed prior to performing the final calculations presented in this paper.

\section{RESULTS AND DISCUSSION}

\subsection{CFD Simulation Results}

\subsubsection{Airflows results}

Fig. 3 presents the velocity fields in the vertical planes $X Y$. Except for the plane which crosses the inlet nozzle, all the planes show a homogeneous distribution of the velocity in the inhalation chamber with an average velocity close to $0.2 \mathrm{~m} \mathrm{~s}^{-1}$. Fig. 4 represents the velocity field in the vertical plane close to the wall on the side where the animal contention tubes for nose-only inhalations are located. The velocity is greater at the bottom of the wall due to the impaction of the jetflow coming from the air inlet nozzle. On the upper part of the wall, the velocity is lower and more homogeneously distributed along the wall with an average value of around $0.2 \mathrm{~m} \mathrm{~s}^{-1}$. This velocity field ensures an area with a moderate airflow and a low turbulence which will not perturb the inhalation of the animals.

Fig. S2 shows the streamlines inside the inhalation chamber. A good distribution of the airflows in the whole chamber is evident, showing no dead volume and allowing the robust mixing of the aerosols and their homogeneous distribution along the wall where the nose-only contention tubes are located.

\subsubsection{Aerosol dispersion results}

Only one particle size of $2 \mu \mathrm{m}$ in aerodynamic diameter was studied as it is fully representative for the present study which will lead to future inhalation studies. Fig. 5 presents the particle mass fraction field in the vertical planes XY. A homogeneous distribution of the aerosol in the chamber with a coefficient of variation (COV) lower than $1 \%$ is seen.

This observation is also consistent with the results in Fig. 6 which presents the particle mass fraction field in the vertical plane close to the wall on the side where the animals inhale aerosol. Homogeneity of the aerosol concentration on the whole plane can be seen with a COV also lower than $1 \%$.

Fig. 7 shows the aerosol deposition flux on the chamber walls. It highlights the low deposition of the aerosol on the wall where the animals inhale. It is because for particles with $2 \mu \mathrm{m}$ 


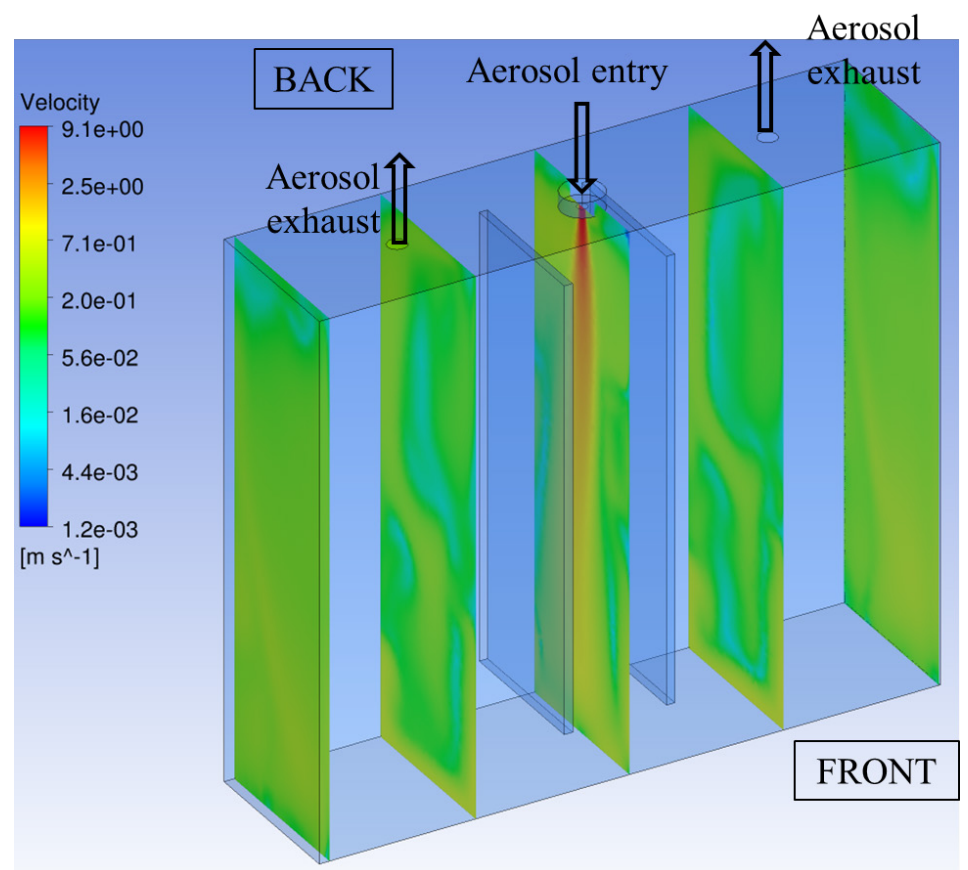

Fig. 3. CFD simulation results of the velocity field in vertical $X Y$ planes.

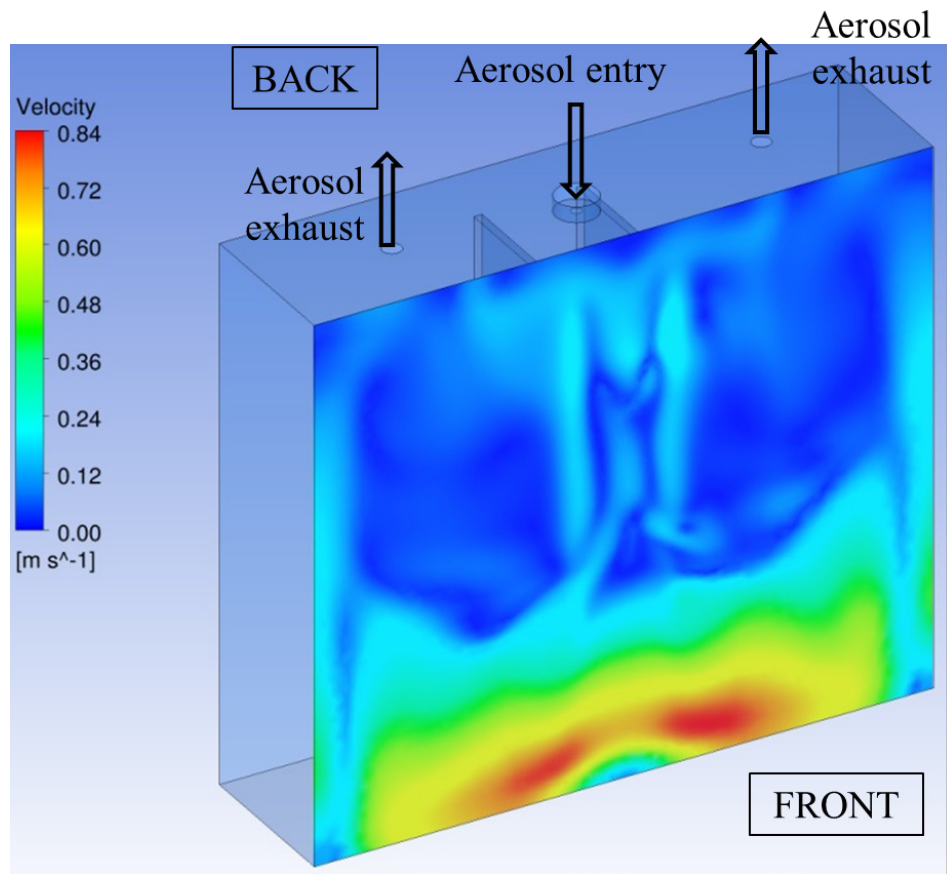

Fig. 4. CFD simulation results of the velocity field near the front wall.

aerodynamic diameter, the turbulence inertial deposition on the vertical wall is quite low and the deposition mainly occurs on horizontal surface due to the gravity effect. The deposition rate on all the walls of the inhalation chamber was $2.6 \%$, which is rather low. Therefore, the aerosol inhaled by the animals would be well representative of that injected in the inlet airflow.

\subsection{Tungsten Particle Characteristics and Issues of Metrology of High-density Particles}

Fig. 8 shows the aerodynamic diameter $\left(D_{a}\right)$ calculated as a function of the electrical mobility 
Aerosol

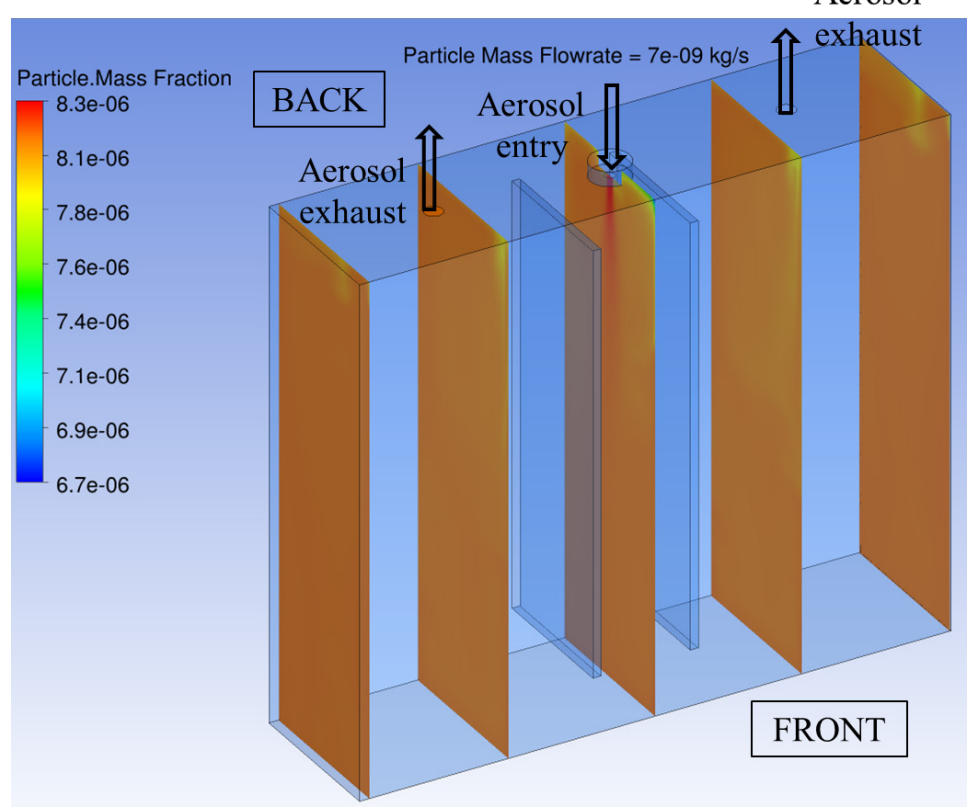

Fig. 5. CFD simulation results of the particle mass fraction field in vertical XY planes.

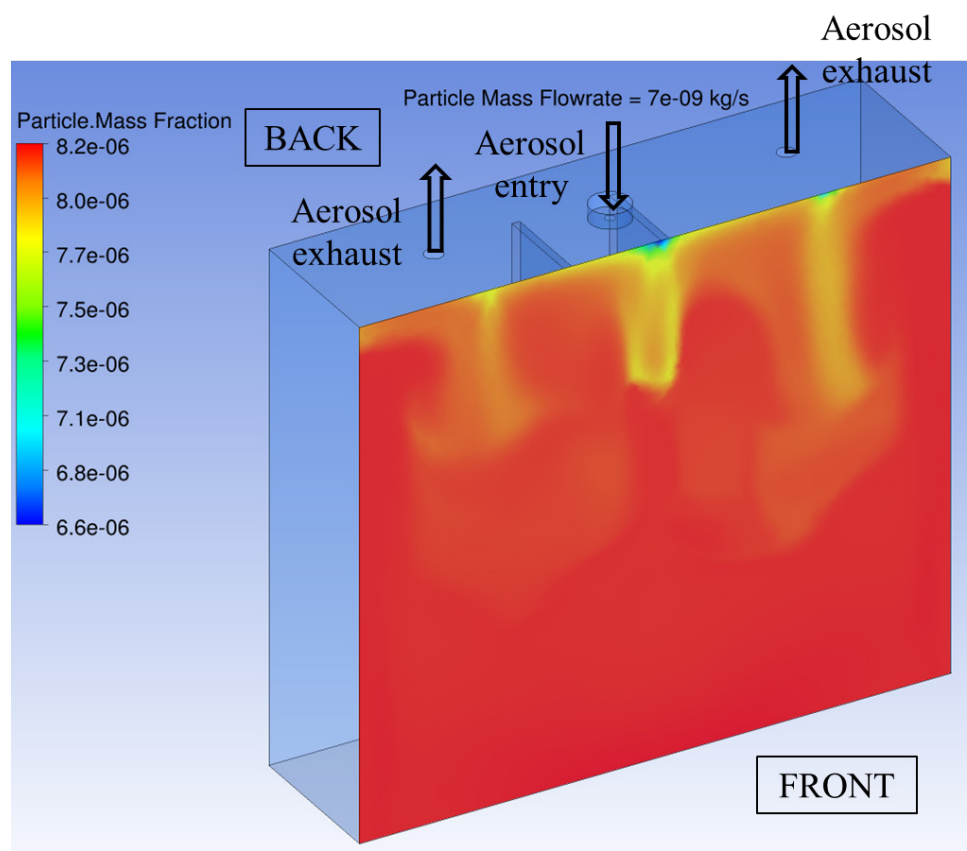

Fig. 6. CFD simulation results of the particle mass fraction field near the front wall.

diameter $\left(D_{m}\right)$ for spherical particles by solving Eq. (1); for practical use, the adjustments of two power functions on the solution of Eq. (1) are also represented. Fig. 8 also shows the evolution of the ratio between these two diameters. As the diameter increases, the $D_{a} / D_{m}$ ratio tends towards an asymptote having a value of $\sqrt{19.3}=4.4$. On the other hand, when the diameter decreases, the ratio $D_{a} / D_{m}$ increases significantly. The value is about 6.6 for $100 \mathrm{~nm}$ particles and exceeds a value of 15 for $5 \mathrm{~nm}$ particles.

These considerations raise several questions about aerosol metrology to control exposure parameters in the inhalation chamber. How to control the generation of a tungsten aerosol in the range of thoracic and alveolar fractions with a mass concentration representative of the average occupational exposure limit value? How to measure the mass particle size distributions 


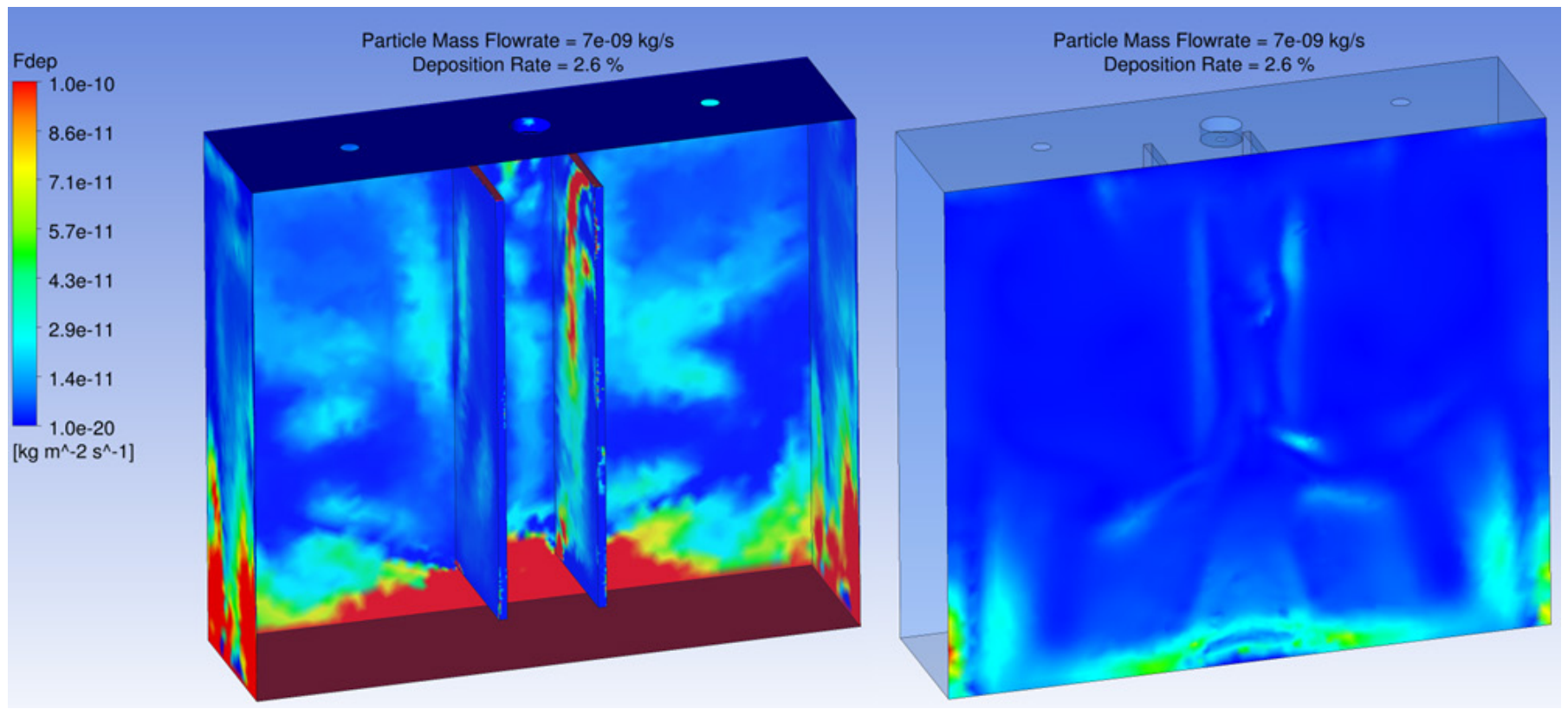

Fig. 7. CFD simulation results of the particle wall deposition flux.

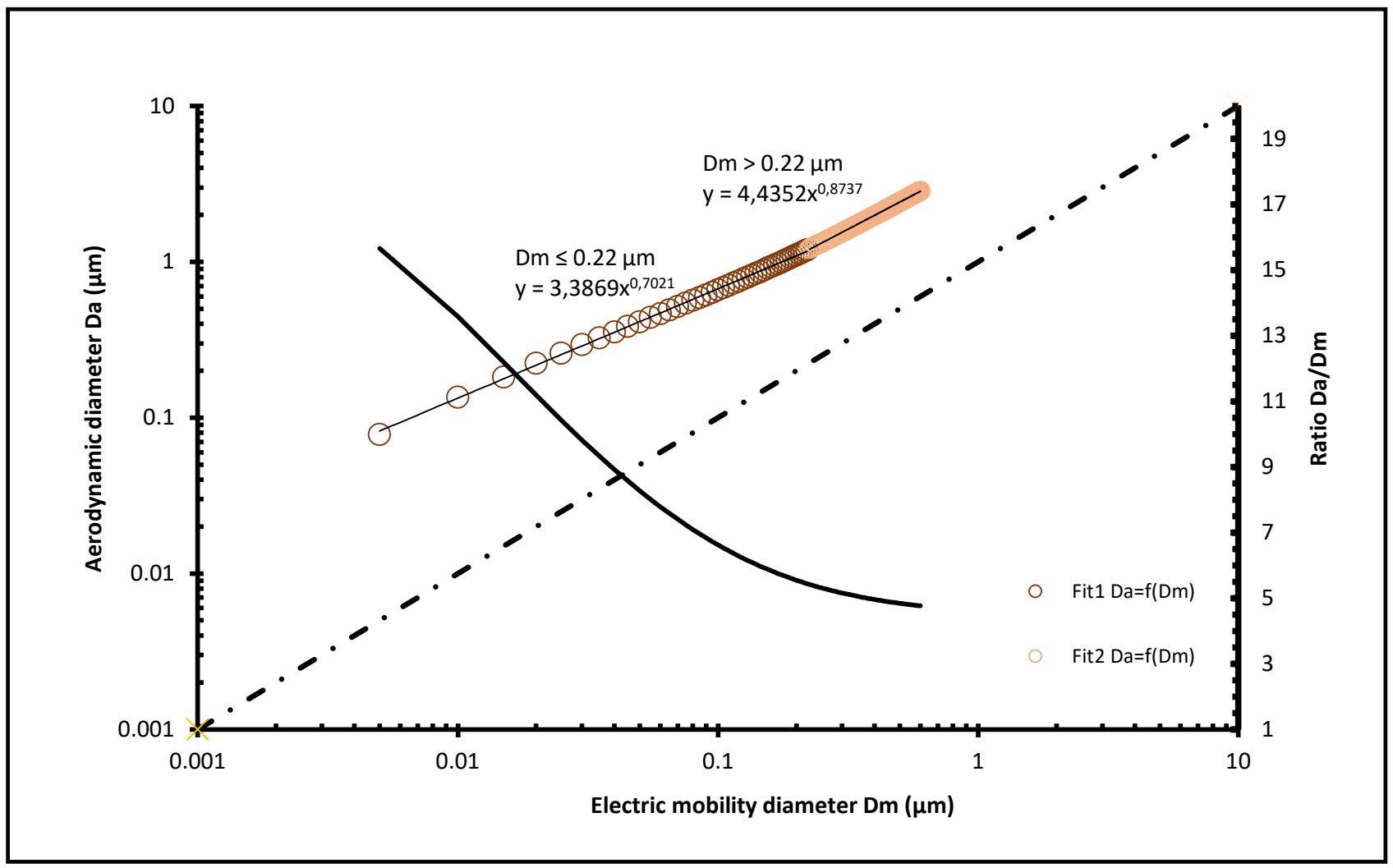

Fig. 8. Comparison between the electrical mobility diameter and the aerodynamic diameter for spherical tungsten particles.

of such aerosols according to the appropriate equivalent diameters (aerodynamic, electrical mobility) for deposition assessment after inhalation?

Since these diameters are used for the prediction of deposition in the respiratory tracts, it is necessary to know how to measure them reliably in order to perform calculations with the International Commission on Radiological Protection (ICRP) model. In this model, the diffusion diameter (assumed to be well represented by the electrical mobility diameter when the particles 
are spherical and non-porous; DeCarlo et al., 2004) is used to calculate the deposition of the particles, in particular by Brownian diffusion, within the range between $0.001 \mu \mathrm{m}$ and about $0.5 \mu \mathrm{m}$. The aerodynamic diameter is used to calculate the deposition by sedimentation and inertial effect for diameters within the range between $0.1 \mu \mathrm{m}$ and $100 \mu \mathrm{m}$. In a practical way, for aerosol behavior modeling, one of the equivalent diameters is selected and the other is calculated, typically with Eq. (1) or with more sophisticated relationship when particle shape factor is known.

Fig. 9 illustrates an example of a respiratory deposition calculation using the Multiple-Path Particle Dosimetry (MPPD) Model (ARA, USA). Calculations are realized for Asymmetric Sprague Dawley Rat Model; the weight is $450 \mathrm{~g}$ and the position is on stomach.

Fig. 9(A) represents the deposited fraction calculated according to particle geometrical diameter (spherical shape is assumed). Solid line corresponds to calculation taking into account the particle density for tungsten $\left(\rho=19.3 \mathrm{gp} \mathrm{cm}^{-3}\right)$. The dashed line corresponds to the calculation when density is set equal to 1 ; in the latter case the geometrical diameter is equal to the aerodynamic diameter. The comparison of the results shows the importance of particle density for calculation of the total deposited fraction for diameters above $0.1 \mu \mathrm{m}$ when inertial effects start to governs particle behavior. The corollary is that knowledge of aerodynamic diameter solely without taking account particle density is not sufficient for relevant calculation for the case of extreme particle density. In this case, both aerodynamic and diffusional equivalent diameters are needed to perform reliable calculation in the size range $0.1-1 \mu \mathrm{m}$.

To illustrate, Fig. 9(B) shows calculation of the deposited fraction according to the lung regions (tracheobronchial region [T.B.] and pulmonary alveolar region [P.]) for the typical aerosol size distribution generated in the inhalation chamber studied here (see below Fig. 10, Fig. 11 and Table 2). For $\rho=19.3 \mathrm{gp} \mathrm{cm}^{-3}$ the calculation is based on knowledge of the electrical mobility size distribution (median diameter equal to $0.43 \mu \mathrm{m}$, geometric standard deviation equal to 1.6) and particle density $\left(19.3 \mathrm{gp} \mathrm{cm}^{-3}\right)$; for $\rho=1$ the calculation is based only on knowledge of aerodynamic size distribution of the aerosol (median diameter equal to $1.88 \mu \mathrm{m}$, geometric standard deviation equal to 1.6). It can be seen that the head fractions exhibit high values and are quite similar. This is due to the fact that aerodynamic particle size distribution is in the micrometric range and, in that region, inertia is the main deposition mechanism.

On the other hand, the tracheobronchial and pulmonary fractions obtained in the two calculations exhibit very low values but are quite different. These deposited fractions are clearly underestimated

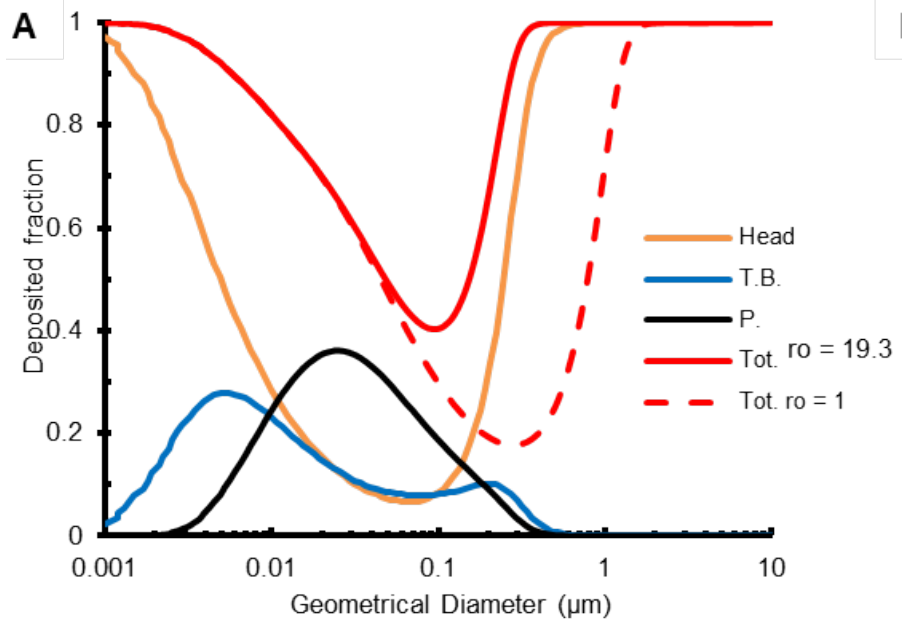

B

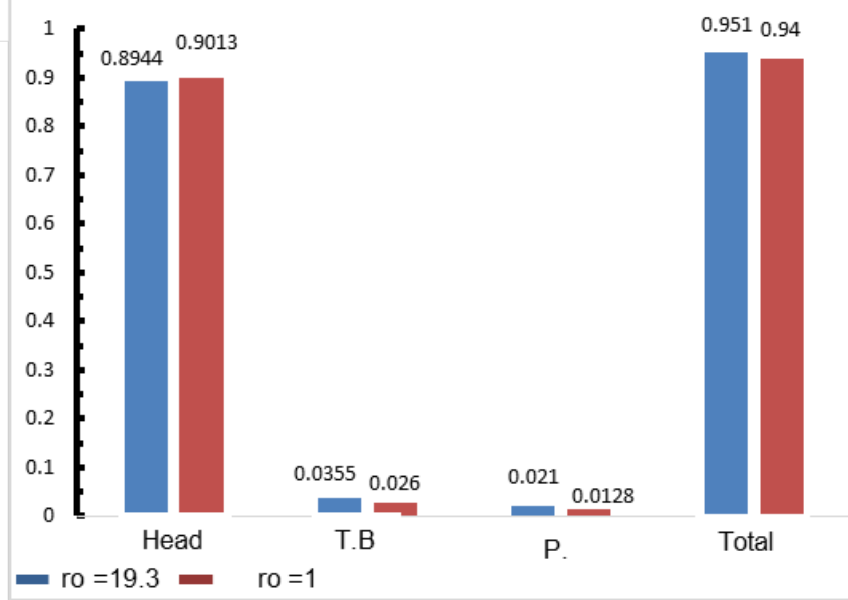

Fig. 9. Deposition of aerosols in the respiratory tracts as a function of particle diameter (assumed spherical) according to MPPD simulations. (A) Calculation of the deposited fraction as a function of particle size in the different lung regions. (B) Calculation of the deposited fraction according to the lung regions (tracheobronchial region [T.B.] and pulmonary alveolar region [P.]) for the typical aerosol size distribution generated in the inhalation chamber. For $\rho=19.3$ the calculation is based on knowledge of the electrical mobility size distribution and particle density; for $\rho=1$ the calculation is based only on knowledge of aerodynamic size distribution of the aerosol. 


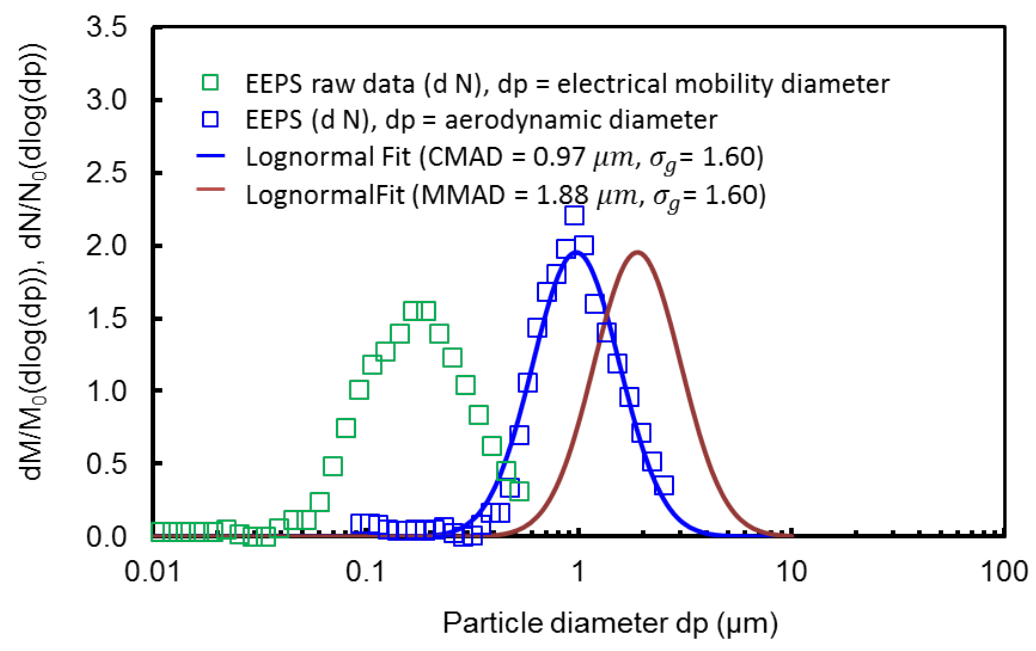

Fig. 10. EEPS size distribution fitted with lognormal function (Hatch and Choate, 1929). CMAD: count median aerodynamic diameter; MMAD: mass median aerodynamic diameter.

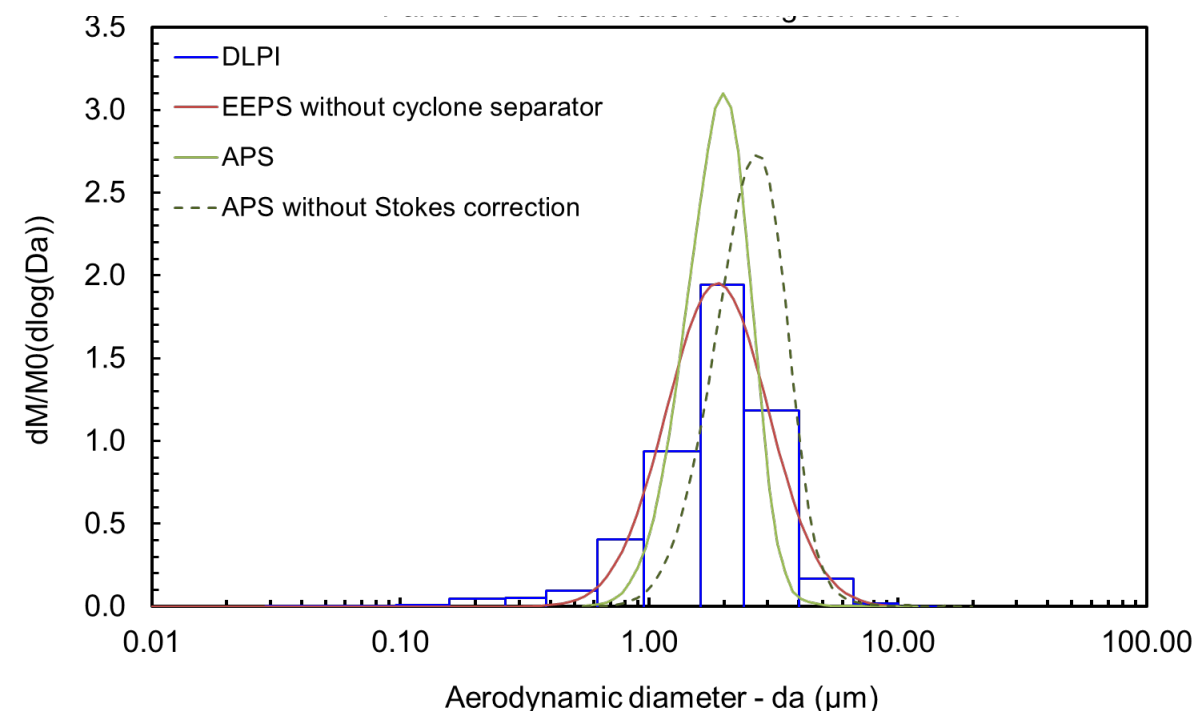

Fig. 11. Particle size distribution of tungsten aerosol measured with the different instruments.

Table 2. Particle size distribution of the tungsten aerosol measured using the different instruments.

\begin{tabular}{|c|c|c|c|c|c|}
\hline Da median DLPI & Da median APS & Da median EEPS (Calculated) & Dm median EEPS & Dm median EEPS & Da median EEPS \\
\hline $1.77 \mu \mathrm{m}$ & $1.89 \mu \mathrm{m}$ & $1.88 \mu \mathrm{m}$ & $0.43 \mu \mathrm{m}$ & $0.17 \mu \mathrm{m}$ & $0.97 \mu \mathrm{m}$ \\
\hline \multicolumn{4}{|c|}{ (Mass) } & \multicolumn{2}{|c|}{ (Number) } \\
\hline
\end{tabular}

when calculated with aerodynamic diameter solely; the discrepancy lies between $27 \%$ and $39 \%$ respectively. In these pulmonary regions, where airflow velocity decreases in comparison to upper airways, the Brownian deposition is enhanced. In this case, the calculation based only of knowledge of aerodynamic diameter is not relevant since it cannot account correctly for Brownian deposition. One should notice that the case studied here for our tested aerosol is not the worst case; discrepancy and density effect could be larger for other values of aerosol median diameters in the range $0.1-1 \mu \mathrm{m}$.

As a consequence, to make reliable calculation in the whole deposition regions for particle sizes in the range $0.1-1 \mu \mathrm{m}$, it is important to take into account one of the characteristic diameters (electrical mobility, aerodynamic) together in any case, with particle density.

It is usually difficult to guarantee relevance of assumptions dealing with sphericity and 
compactness of the particles present in an aerosol generation process, in particular due to lack of information on the particulate material and occurrence of particles aggregation during aerosolization of powders caused by instruments used. Therefore, the use of Eq. (1) to relate the electrical mobility diameter and aerodynamic diameter can still be discussed. It is therefore most important to make direct measurements of the particle size distributions of aerosols to monitor these different equivalent diameters especially when the size spectrum is within the transition regime between $0.1 \mu \mathrm{m}$ and $1 \mu \mathrm{m}$ (when standard conditions for temperature and pressure applies) and when there are large differences between $D_{m}$ and $D_{a}$ which is the case for tungsten.

\subsubsection{Size distribution results}

The reference particle size distribution, providing the mass distribution of the aerodynamic diameter, is considered to be measured by the DLPI. It should be noted that during measurements carried out in parallel with the filter holder, the mass concentrations provided by the two devices were always very close with variability of less than $5 \%$.

Our results show that the experimental set-up as we designed it, i.e., a cyclone at the outlet of the RBG 1000 generator and the strategy to dilute the powder of interest, allowed us to achieve the target aerosol mass concentration of $10 \mathrm{mg} \mathrm{m}^{-3}$. Moreover, the APS 3321, which performs live monitoring of the aerosol mass concentration, enabled us to evaluate the stability of this concentration over a given period of time in the inhalation chamber. Fig. $\mathrm{S} 3$ shows results of measurements carried out with the APS over a length of time during which the generator is started up and maintained in a generation mode with the parameters described in the "Methods" section. The net increase in mass concentration is observed as the generator brush comes into contact with the powder, and then remains relatively stable at the desired concentration for a period of at least 30 minutes, which represents the duration of future animal aerosol exposure experiments.

The comparison between the DLPI and the APS allows to test the ability of the APS to measure very dense particles for which the relaxation time, in the flow regime of the time of flight (TOF) of the instrument, is no longer a unique function of the aerodynamic diameter and requires the use of the Stokes correction proposed by Wang and John (1987). Moreover, given the very large difference between the aerodynamic diameter of the particles and their geometric diameter, this comparison makes it possible to test the ability of the APS to detect relatively small particles, at the sensitivity limit of the systems for detecting the light scattered by these particles between the laser beams of the TOF, although they are quite within the measurement range in terms of aerodynamic diameter.

To perform the measurements with the EEPS, and given the relatively large aerodynamic diameter of the aerosol, we removed the cyclone at the inlet of the instrument which is sized to have an aerodynamic cut-off diameter of $1 \mu \mathrm{m}$. The basic particle size distribution expressed by the EEPS is a count distribution as a function of the electrical mobility diameter. In order to make a comparison with the measurements made by the DLPI, we expressed the number distribution measured by EEPS as a function of aerodynamic diameter using the equations shown in Fig. 8 and paying particular attention to normalizing the distribution with respect to dlog $D_{a}$ taking into account that the ratio $D_{m} / D_{a}$ is not constant in the transition regime according to particle size. Then the size distribution produced is fitted with a lognormal function to obtain the count median aerodynamic diameter and the geometric standard deviation, and we use the properties of the lognormal function (Hatch and Choate, 1929) to obtain the corresponding mass distribution and its mass median aerodynamic diameter (MMAD) as described in Fig. 10. This method is preferred to determine the mass median diameter as the mass size distribution calculated directly from the count size distribution is slightly truncated owing to the upper limit of the EEPS in terms of electrical mobility diameter.

The particle size distributions obtained using the different instruments, analyzed as described in the paragraph above, are shown in Fig. 11.

The MMAD determined by the DLPI is $1.77 \mu \mathrm{m}$; the MMAD determined by the APS with Stokes correction is $1.89 \mu \mathrm{m}$. The count median electrical mobility diameter determined by EEPS is $0.17 \mu \mathrm{m}$. Values measured by the different instruments and calculations of diameters are shown in Table 2.

The agreement obtained between DLPI and APS is remarkable as the particle geometrical diameters are in the submicron range and very close to the detection limit of the APS in terms of 
scattered light. However, it should be noted that these results could not be reproduced using another TSI APS 3321 even when the laser beam power was set at 100\% (instead of the standard value of $75 \%$ ), which raises the question of the sensitivity setting of the particle passage detection systems between the TOF laser beams for (electrical mobility) diameters smaller than about $0.5 \mu \mathrm{m}$. Indeed, if we compare the percentages of representative events, clear difference between the two instruments can be noticed. The reference APS indicates $20 \%$ of Event Type 1, $80 \%$ of Event Type 2 and $0 \%$ of Event Type 3. Event Type 1 is caused by particles that scattered light above the detection threshold when passing the first laser beam of the TOF buffer but not enough to exceed the threshold when crossing the second laser beam; the APS is not able to determine aerodynamic diameter of particles creating such event. Event Type 2 corresponds to a particle with a valid event that allows determining the TOF, and Event Type 3 corresponds to coincidence when a second particle enters the TOF buffer before the first one completes its passage. The value of 20\% for Event Type 1 detected by the reference APS clearly shows that a certain fraction of particles is not taken into account for aerodynamic sizing. This relatively high rate of Event Type 1 is probably due to the fact that a portion of the particles have the size close to the detection threshold of scattered light. Nevertheless $80 \%$ of particles detected (corresponding to Event Type 2) were aerodynamically "sizeable." When the same aerosol was measured with another APS, $100 \%$ of events were of Type 1 and no aerodynamic sizing was possible in this case. These results demonstrate the necessity of deep understanding of theory of operation of aerosol instrumentation and cross checking with different techniques when used to characterize atypical aerosols.

\section{CONCLUSION}

We established high concordance between the measurements obtained with the DLPI, the APS, and the EEPS. In addition, we developed a methodology for analyzing electrical mobility diameter values from the EEPS that enables the measurement of particles beyond the intended range of the instrument as well as the range of previously studied aerodynamic sizes. These results demonstrated the influence of particle density on the response of the APS 3321 and validated the Stokes correction for densities as high as 19.3, but we were unable to reproduce them with a second APS 3321 unit, which raises a question about the internal apparatus settings for optimizing the particle detection efficiency of (electrical mobility) diameters below approximately $0.5 \mu \mathrm{m}$ but having aerodynamic diameters fully in the range of operation. Overall, our findings agree with previously published works and confirm the importance of precisely characterizing aerosols that will be used in inhalation toxicology studies.

Our project explores the neurobiological effects of tungsten inhalation in rats. Following the "neuroinflammatory hypothesis" (Jayaraj et al., 2017), which links particulate pollution and neurodegenerative disease, future research will examine the potential consequences of exposure on microglial cell recruitment and morphology in specific brain regions, namely, the olfactory bulbs, frontal cortex, and sub-ventricular zone. Impaired neurogenesis, which is associated with neuroinflammation, is a topic of particular interest. Thus, we will investigate whether modulating neuroinflammation affects the survival and differentiation of stem cells in the rostral migratory stream (RMS), an active neurogenic zone for the olfactory system that is vulnerable to inhaled pollution, by observing the interactions between microglial cells and migrating neuroblasts.

\section{ACKNOWLEDGMENTS}

This work was supported by IRSN. The authors wish to thank Sylvain Fauvel for his helpful contribution to this work. Dr. Laurence Roy and Dr. Dmitry Klokov are acknowledged for careful reading of the manuscript.

\section{DISCLAIMER}

Reference to any companies or specific commercial products does not constitute any conflict of interests. 


\section{SUPPLEMENTARY MATERIAL}

Supplementary data associated with this article can be found in the online version at https://doi.org/10.4209/aaqr.200504

\section{REFERENCES}

Agency for Toxic Substances and Disease Registry (ATSDR) (2015). Addendum to the Toxicological Profile for Tungsten. Agency for Toxic Substances and Disease Registry, Division of Toxicology and Human Health Sciences, Atlanta, GA 30333. https://www.atsdr.cdc.gov/toxprofiles/Tungs ten_Addendum_508.pdf

Anderson, J.L., Apostoaei, A.I., Yiin, J.H., Fleming, D.A., Tseng, C.Y., Chen, P.H. (2016). Internal exposure to uranium in a pooled cohort of gaseous diffusion plant workers. Radiat. Prot. Dosim. 168, 471-477. https://doi.org/10.1093/rpd/ncv357

Andre, S., Charuau, J., Rateau, G., Vavasseur, C., Métivier, H. (1989). Design of a new inhalation device for rodents and primates. J. Aerosol Sci. 20, 647-656. https://doi.org/10.1016/00218502(89)90053-0

Bolt, A.M., Mann, K.K. (2016). Tungsten: An emerging toxicant, alone or in Combination. Curr. Environ. Health Rep. 3, 405-415. https://doi.org/10.1007/s40572-016-0106-z

Bolton, J.L., Marinero, S., Hassanzadeh, T., Natesan, D., Le, D., Belliveau, C., Mason, S.N., Auten, R.L., Bilbo, S.D. (2017). Gestational exposure to air pollution alters cortical volume, microglial morphology, and microglia-neuron interactions in a sex-specific manner. Front. Synaptic Neurosci. 9, 10. https://doi.org/10.3389/fnsyn.2017.00010

Buckley, A., Warren, J., Hodgson, A., Marczylo, T., Ignatyev, K., Guo, C., Smith, R. (2017). Slow lung clearance and limited translocation of four sizes of inhaled iridium nanoparticles. Part. Fibre Toxicol. 14, 5. https://doi.org/10.1186/s12989-017-0185-5

Calderon-Garciduenas, L., Reynoso-Robles, R., Vargas-Martinez, J., Gomez-Maqueo-Chew, A., Perez-Guille, B., Mukherjee, P.S., Torres-Jardon, R., Perry, G., Gonzalez-Maciel, A. (2016). Prefrontal white matter pathology in air pollution exposed Mexico City young urbanites and their potential impact on neurovascular unit dysfunction and the development of Alzheimer's disease. Environ. Res. 146, 404-417. https://doi.org/10.1016/j.envres.2015.12.031

Carlini, E.A. (1973). Farmacologia Prática Sem Aparelhagem. São Paulo: Sarvier: 198.

Chae, N., Lee, M.H., Choi, S., Park, B., Song, J.S. (2019). Aerodynamic diameter and radioactivity distributions of radioactive aerosols from activated metals cutting for nuclear power plant decommissioning. J. Hazard. Mater. 369, 727-745. https://doi.org/10.1016/j.jhazmat.2019.02.093

Chen, L.C., Lippmann, M. (2015). Inhalation toxicology methods: The generation and characterization of exposure atmospheres and inhalational exposures. Curr. Protoc. Toxicol. 63, 2424 21-24 2423. https://doi.org/10.1002/0471140856.tx2404s63

Davies, N.C. (1968). The entry of aerosols into sampling tubes and heads. Br. J. Appl. Phys. 25, 921-932.

DeCarlo, P.F., Slowik, J.G., Worsnop, D.R., Davidovits, P., Jimenez, J.L. (2004). Particle morphology and density characterization by combined mobility and aerodynamic diameter measurements. Aerosol Sci. Technol. 38, 1185-1205. https://doi.org/10.1080/027868290903907

Disdier, C., Chalansonnet, M., Gagnaire, F., Gate, L., Cosnier, F., Devoy, J., Saba, W., Lund, A.K., Brun, E., Mabondzo, A. (2017). Brain inflammation, blood brain barrier dysfunction and neuronal synaptophysin decrease after inhalation exposure to titanium dioxide nano-aerosol in aging rats. Sci. Rep. 7, 12196. https://doi.org/10.1038/s41598-017-12404-5

Dumkova, J., Smutna, T., Vrlikova, L., Le Coustumer, P., Vecera, Z., Docekal, B., Mikuska, P., Capka, L., Fictum, P., Hampl, A., Buchtova, M. (2017). Sub-chronic inhalation of lead oxide nanoparticles revealed their broad distribution and tissue-specific subcellular localization in target organs. Part. Fibre Toxicol. 14, 55. https://doi.org/10.1186/s12989-017-0236-y

Elder, A., Gelein, R., Silva, V., Feikert, T., Opanashuk, L., Carter, J., Potter, R., Maynard, A., Ito, Y., Finkelstein, J., Oberdorster, G. (2006). Translocation of inhaled ultrafine manganese oxide particles to the central nervous system. Environ. Health Perspect. 114, 1172-1178. https://doi.org/10.1289/ehp.9030 
Gate, L., Knudsen, K.B., Seidel, C., Berthing, T., Chezeau, L., Jacobsen, N.R., Valentino, S., Wallin, H., Bau, S., Wolff, H., Sebillaud, S., Lorcin, M., Grossmann, S., Viton, S., Nunge, H., Darne, C., Vogel, U., Cosnier, F. (2019). Pulmonary toxicity of two different multi-walled carbon nanotubes in rat: Comparison between intratracheal instillation and inhalation exposure. Toxicol. Appl. Pharmacol. 375, 17-31. https://doi.org/10.1016/j.taap.2019.05.001

George, I., Uboldi, C., Bernard, E., Sobrido, M.S., Dine, S., Hagege, A., Vrel, D., Herlin, N., Rose, J., Orsiere, T., Grisolia, C., Rousseau, B., Malard, V. (2019). Toxicological assessment of ITER-like tungsten nanoparticles using an in Vitro 3D human airway epithelium model. Nanomaterials 9, 1374. https://doi.org/10.3390/nano9101374

Hatch, T., Choate, S.P. (1929). S Statistical description of the size properties of non uniform particulate substances. J. Franklin Inst. 207, 369-387. https://doi.org/10.1016/S00160032(29)91451-4

Heusinkveld, H.J., Wahle, T., Campbell, A., Westerink, R.H.S., Tran, L., Johnston, H., Stone, V., Cassee, F.R., Schins, R.P.F. (2016). Neurodegenerative and neurological disorders by small inhaled particles. Neurotoxicology 56, 94-106. https://doi.org/10.1016/j.neuro.2016.07.007

Ibanez, C., Suhard, D., Tessier, C., Delissen, O., Lestaevel, P., Dublineau, I., Gourmelon, P. (2014). Intranasal exposure to uranium results in direct transfer to the brain along olfactory nerve bundles. Neuropathol. Appl. Neurobiol. 40, 477-488. https://doi.org/10.1111/nan.12061

Ibanez, C., Suhard, D., Elie, C., Ebrahimian, T., Lestaevel, P., Roynette, A., Dhieux-Lestaevel, B., Gensdarmes, F., Tack, K., Tessier, C. (2019). Evaluation of the nose-to-brain transport of different physico-chemical forms of uranium after exposure via inhalation of a $\mathrm{UO}_{4}$ aerosol in the rat. Environ. Health Perspect. 127, 97010. https://doi.org/10.1289/EHP4927

Jayaraj, R.L., Rodriguez, E.A., Wang, Y., Block, M.L. (2017). Outdoor ambient air pollution and neurodegenerative diseases, the neuroinflammation hypothesis. Curr. Environ. Health Rep. 4: 166-179. https://doi.org/10.1007/s40572-017-0142-3

Levesque, S., Surace, M.J., McDonald, J., Block, M.L. (2011). Air pollution \& the brain: Subchronic diesel exhaust exposure causes neuroinflammation and elevates early markers of neurodegenerative disease. J. Neuroinflammation 8, 105. https://doi.org/10.1186/1742-2094-8-105

Lucchini, R.G., Dorman, D.C., Elder, A., Veronesi, B. (2012). Neurological impacts from inhalation of pollutants and the nose-brain connection. Neurotoxicology 33, 838-841. https://doi.org/1 0.1016/j.neuro.2011.12.001

Lucci, F., Tan, W., Krishnan, Hoeng, J., Vanscheeuwijck, P., Jaeger, R., Kuczaj, A.K. (2019). Experimental and computational investigation of a nose-only exposure chamber. Aerosol Sci. Technol. 54, 277-290. https://doi.org/10.1080/02786826.2019.1687843

Matthew, E., Warden, G., Dedman, J. (2001). A murine model of smoke inhalation. american journal of physiology. Lung Cell. Mol. Physiol. 280, L716-L723. https://doi.org/10.1152/ajplun g.2001.280.4.L716

McGuinn, L.A., Windham, G.C., Kalkbrenner, A.E., Bradley, C., Di, Q., Croen, L.A., Fallin, M.D., Hoffman, K., Ladd-Acosta, C., Schwartz, J., Rappold, A.G., Richardson, D.B., Neas, L.M., Gammon, M.D., Schieve, L.A., Daniels, J.L. (2019). Early life exposure to air pollution and autism spectrum disorder: Findings from a multisite case-control study. Epidemiology 31, 103-114. https://doi.org/10.1097/EDE.0000000000001109

Nerisson, P., Simonin, O., Ricciardi, L., Douce, A., Fazileabasse, J. (2011). Improved CFD transport and boundary conditions models for low-inertia particles. Comput. Fluids 40, 79-91. https://doi.org/10.1016/j.compfluid.2010.08.013

Oberdorster, G., Elder, A., Rinderknecht, A. (2009). Nanoparticles and the brain: Cause for concern? J. Nanosci. Nanotechnol. 9, 4996-5007. https://doi.org/10.1166/jnn.2009.gr02

Oberdorster, G., Sharp, Z., Atudorei, V., Elder, A., Gelein, R., Kreyling, W., Cox, C. (2004). Translocation of inhaled ultrafine particles to the brain. Inhalation Toxicol. 16, 437-445. https://doi.org/10.1080/08958370490439597

Oudin, A., Forsberg, B., Adolfsson, A.N., Lind, N., Modig, L., Nordin, M., Nordin, S., Adolfsson, R., Nilsson, L.G. (2016). Traffic-related air pollution and dementia incidence in northern Sweden: A longitudinal study. Environ. Health Perspect. 124, 306-312. https://doi.org/10.1289/ehp.14 08322

Peillon, S., Fauvel, S., Chagnot, C., Gensdarmes, F. (2017). Aerosol charaterization and particle scrubbing efficiency of underwater operations during laser cutting of steel components for 
dismantling of nuclear facilities. Aerosol Air Qual. Res. 17, 1363-1373. https://doi.org/10.420 9/aaqr.2016.09.0421

Phalen, R.F. (1997). Methods in Inhalation Toxicology. Boca Raton, FLCRC Press.

Prajapati, M.V., Adebolu, O.O., Morrow, B.M., Cerreta, J.M. (2017). Original Research: Evaluation of pulmonary response to inhaled tungsten (IV) oxide nanoparticles in golden Syrian hamsters. Exp. Biol. Med. 242, 29-44. https://doi.org/10.1177/1535370216665173

Pujalte, I., Dieme, D., Haddad, S., Serventi, A.M., Bouchard, M. (2017). Toxicokinetics of titanium dioxide $\left(\mathrm{TiO}_{2}\right)$ nanoparticles after inhalation in rats. Toxicol. Lett. 265, 77-85. https://doi.org/ 10.1016/j.toxlet.2016.11.014

Radcliffe, P.M., Olabisi, A.O., Wagner, D.J., Leavens, T., Wong, B.A., Struve, M.F., Chapman, G.D. Wilfong, E.R., Dorman, D.C. (2009). Acute sodium tungstate inhalation is associated with minimal olfactory transport of tungsten $\left({ }^{188} \mathrm{~W}\right)$ to the rat brain. Neurotoxicology $30,445-450$. https://doi.org/10.1016/j.neuro.2009.02.004

Radcliffe, P.M., Leavens, T.L., Wagner, D.J., Olabisi, A.O., Struve, M.F., Wong, B.A., Tewksbury, E., Chapman, G.D., Dorman, D.C. (2010). Pharmacokinetics of radiolabeled tungsten $\left({ }^{188} \mathrm{~W}\right)$ in male Sprague-Dawley rats following acute sodium tungstate inhalation. Inhalation Toxicol. 22, 69-76. https://doi.org/10.3109/08958370902913237

Rihn, B., Kauffer, E., Martin, P., Coulais, C., Villa, M., Bottin, M.C., Vigneron, J.C., Edorh, A., Martinet, N. (1996). Short-term crocidolite inhalation studies in mice: Validation of an inhalation chamber. Toxicology 109, 147-156. https://doi.org/10.1016/0300-483x(96)03325-2

Roedel, E.Q., Cafasso, D.E., Lee, K.W., Pierce, L.M. (2012). Pulmonary toxicity after exposure to military-relevant heavy metal tungsten alloy particles. Toxicol. Appl. Pharmacol. 259, 74-86. https://doi.org/10.1016/j.taap.2011.12.008

Rondeau, A., Peillon, S., Roynette, A., Sabroux, J.C., Gelain, T., Gensdarmes, F., Rohde, V., Grisolia, C., Chassefière, E. (2015). Characterization of dust particles produced in an all-tungsten wall tokamak and potentially mobilized by airflow. J. Nucl. Mater. 463, 873-876. https://doi.org/10. 1016/j.jnucmat.2014.12.051

Sachdeva, S., Pant, S.C., Kushwaha, P., Bhargava, R., Flora, S.J. (2015). Sodium tungstate induced neurological alterations in rat brain regions and their response to antioxidants. Food Chem. Toxicol. 82, 64-71. https://doi.org/10.1016/j.fct.2015.05.003

Sagot, B., Forthomme, A., Yahia, L.A.A., De La Bourdonnaye, G. (2017). Experimental study of cyclone performance for blow-by gas cleaning applications. J. Aerosol Sci. 110, 53-69. https://doi.org/10.1016/j.jaerosci.2017.05.009

Samson, E., Piot, I., Zhivin, S., Richardson, D.B., Laroche, P., Serond, A.P., Laurier, D., Laurent, O. (2016). Cancer and non-cancer mortality among french uranium cycle workers: The tracy cohort. BMJ Open 6, e010316. https://doi.org/10.1136/bmjopen-2015-010316

Sclichting, H. (1979). Boundary-Layer Theory. Seventh edition, Mc Graw-Hill, New York.

Shan, D., Xie, Y., Ren, G., Yang, Z. (2013). Attenuated effect of tungsten carbide nanoparticles on voltage-gated sodium current of hippocampal CA1 pyramidal neurons. Toxicol. in Vitro 27, 299-304. https://doi.org/10.1016/j.tiv.2012.08.025

Uboldi, C., Sanles Sobrido, M., Bernard, E., Tassistro, V., Herlin-Boime, N., Vrel, D., Garcia-Argote, S., Roche, S., Magdinier, F., Dinescu, G., Malard, V., Lebaron-Jacobs, L., Rose, J., Rousseau, B., Delaporte, P., Grisolia, C., Orsiere, T. (2019). In vitro analysis of the effects of ITER-like tungsten nanoparticles: cytotoxicity and epigenotoxicity in BEAS-2B cells. Nanomaterials 9, 1233. https://doi.org/10.3390/nano9091233

Wang, H.C., John, W. (1987). Particle density correction for the aerodynamic particle sizer. Aerosol Sci. Technol. 6, 191-198. https://doi.org/10.1080/02786828708959132

Wang, Y., Wang, B., Zhu, M.T., Li, M., Wang, H.J., Wang, M., Ouyang, H., Chai, Z.F., Feng, W.Y., Zhao, Y.L. (2011). Microglial activation, recruitment and phagocytosis as linked phenomena in ferric oxide nanoparticle exposure. Toxicol. Lett. 205, 26-37. https://doi.org/10.1016/j.toxlet. 2011.05.001

Wasel, O., Freeman, J.L. (2018). Comparative assessment of tungsten toxicity in the absence or presence of other metals. Toxics 6, 66. https://doi.org/10.3390/toxics6040066

Wen, R., Yang, X., Hu, L., Sun, C., Zhou, Q., Jiang, G. (2016). Brain-targeted distribution and high retention of silver by chronic intranasal instillation of silver nanoparticles and ions in SpragueDawley rats. J. Appl. Toxicol. 36, 445-453. https://doi.org/10.1002/jat.3260 